\title{
Proceedings of trainee presentations at the 2008 meeting of the Scottish Otolaryngological Society, 9 May 2008, Pitlochry, Scotland, UK
}

\author{
Removal of fish bones from laryngopharynx: novel \\ technique using sheathed nasopharyngoscope \\ D Bowyer, G Robertson \\ From the Royal Infirmary of Edinburgh, Scotland, UK.
}

\section{Background}

Fish bones that lodge distally in the laryngopharynx are challenging to remove; previous studies have found that up to half necessitate general anaesthesia.

\section{Objective}

To describe the novel use of a single-use, channelled sheath with a standard nasopharyngoscope to remove fish bones from the laryngopharynx.

\section{Equipment and method}

A standard flexible nasopharyngoscope was used to assess patients with a history of fish bone impaction and normal per oral examination. Slid over the endoscope, a single-use, channelled sheath with a $2.1 \mathrm{~mm}$ working channel was placed. Endoscopic examination was performed. Once the fish bone was identified, disposable laryngeal biopsy forceps were introduced through the instrument channel to grasp one end of the bone and remove it. This technique has been successfully used for five consecutive patients with distal fish bone impaction.

\section{Conclusion}

We describe a novel technique for removing fish bones that previously would have required general anaesthesia. The method is simple to perform and uses inexpensive equipment that is discarded after use.

\section{Prospective, randomised, double-blinded, controlled trial of management of recurrent nosebleeds in children: antiseptic cream alone versus antiseptic cream with nasal cautery}

N Calder, S Kang, L Fraser, T Kunanandan, J Montgomery, H Kubba

From the Royal Hospital for Sick Children, Glasgow, Scotland, UK.

\section{Objective}

To establish whether a treatment regimen of silver nitrate cautery plus four weeks of antiseptic cream is superior to antiseptic cream alone in the management of paediatric epistaxis.

\section{Method}

Patients with epistaxis and visible anterior septal vessels were invited to participate. Patients who agreed to participate were then randomised to receive either the study treatment or the control. Treatment patients received silver nitrate cautery followed by a four week course of Naseptin antiseptic cream twice daily. Control patients received sham cautery followed by four weeks' Naseptin cream.

Results

One hundred and nine patients were randomised, with results available for 93 (85 per cent). Of those receiving cautery plus antiseptic cream, 21/46 (45.7 per cent) had no bleeding in the following four weeks; of those receiving only antiseptic cream, $14 / 47$ (29.8 per cent) had no bleeding (chi-square $=2.49, \quad p=0.114 ;$ relative risk reduction $(\mathrm{RRR})=23$ per cent; number needed to treat $(\mathrm{NNT})=6.3)$.

\section{Conclusion}

Silver nitrate cautery gives a small additional benefit to antiseptic cream in the management of recurrent paediatric epistaxis, in those patients with visible vessels on the anterior septum.

\section{Direct listing for tonsillectomy: implementation and patients' satisfaction}

D Clark, M Shakeel, J Newton, B Ram

From the Aberdeen Royal Infirmary, Aberdeen, Scotland, UK

\section{Introduction}

Various factors led to a redesign of the ENT out-patient services in the Grampian region of Scotland. The main change involved setting up a direct referral system for patients who may be suitable for tonsillectomy. This was introduced initially in Kincardine, Aberdeenshire, in September 2004. If patients' referral letters contained sufficient information, the consultant could immediately make the decision of whether to place the patient on the theatre list, rather than delay the decision until the patient's first out-patients appointment (which could be several weeks hence).

Aim

To evaluate the impact of direct tonsillectomy referral.

\section{Method}

Part one, patient satisfaction: Patients who had been through the direct referral system via the Kincardine clinic between July 2005 and May 2006 consented to take part in the audit at their pre-assessment clinic appointment. Patients were then sent a covering letter and questionnaire, 10 days after their hospital discharge (following surgery).

Part two, comparison: Data were collected retrospectively on waiting times and different referral routes in the Grampian region. Patients from Kincardine were identified first. The date these patients were placed on the theatre waiting list (between October 2004 and August 2005) was used as a marker to guide the selection and inclusion of patients from other areas. 
Results

Part one: Eighteen questionnaires were posted and 12 returned. All patients were seen at the nurse-led preassessment clinic, and received verbal as well as printed information about their operation. Of the 12 respondents, 11 were happy with the direct listing system and one was unsure.

Part two: A total of 73 patients were included in this dataset, from Kincardine and other areas in the Grampian region. Ninety-two per cent of direct referrals underwent surgery within 26 weeks of referral (by comparison, the Scottish Executive target was set at 26 weeks, from referral to outpatient appointment). The remaining $8 \%$ (one patient) could not attend the original date given for surgery. Eighty three percent of all the other referrals waited over the 26 week period for surgery.

Conclusion: Overall, these results indicate that the direct referral system could greatly reduce the length of time patients wait for surgery. There is potential to extend this system to other areas within the Grampian National Health Service Trust.

\section{Parotid lymphoma in west Scotland: review of diagnosis, management and 'core' issues}

D P Crampsey, K MacKenzie

From the Glasgow Royal Infirmary, Scotland, UK, in conjunction with the West of Scotland Managed Clinical Network for Lymphoma.

\section{Objectives}

To establish whether there was a requirement for a network policy on the management of suspected intraparotid lymphoma, and to answer the question, 'can parotid lymphoma be adequately diagnosed, staged and treated on the basis of a core biopsy, within the West of Scotland?'

\section{Method}

We identified 22 patients from the West of Scotland Managed Clinical Network database who had been diagnosed between 2003 and 2005 with lymphoma of the parotid region (nodal or extranodal). These 22 cases were reviewed, assessing specifically their investigation and diagnosis (compared with the World Health Organization classification of parotid lymphoma).

\section{Results}

Three of the 22 patients underwent core biopsy to diagnose and type their lymphoma. All these procedures were performed within a single centre.

\section{Conclusion}

It is possible to successfully perform core biopsy of parotid lymphoma lesions (generally under ultrasonic guidance). This may obviate the need for open procedures. Close collaboration with haematology, pathology, radiology and head and neck colleagues is required.

\section{Ties and white coats: to wear or not to wear? Patients' attitudes to doctors' appearance in the otolaryngology out-patient clinic}

I F Hathorn, S K Ross, A J Cain

From the Raigmore Hospital, Inverness, Scotland, UK.

\section{Objectives}

To determine patients' attitudes to otolaryngology doctors' workwear in the out-patient clinic, in view of recent
Department of Health recommendations that neck-ties, white coats, long-sleeve shirts and jewellery below the elbow should be avoided.

\section{Method}

One hundred patients attending the otolaryngology outpatient department completed a questionnaire covering the areas raised by the Department of Health recommendations.

\section{Results}

Eighty-eight per cent of patients felt a doctor's appearance was important. The majority thought ties and white coats should not be worn (76 and 63 per cent, respectively). Forty-six per cent felt collared shirts should be worn; of these patients, 89 per cent thought that it did not matter whether the shirts were long- or short-sleeved. The use of a uniform was supported by 9 per cent. Eighty-seven per cent felt that it was either acceptable or of no consequence whether a doctor wore jewellery or a watch.

\section{Conclusion}

Adoption of the Department of Health recommendations would not be unpopular with ENT out-patients. However, further work is warranted before established traditions are abandoned.

\section{Impact of endonasal dacryocystorhinostomy on patient quality of life as assessed by the Glasgow benefit inventory}

I F Hathorn, P M Spielmann, S F Ahsan, A J Cain, P S White* From the Raigmore Hospital, Inverness, and the ${ }^{*}$ Ninewells Hospital, Dundee, Scotland, UK.

\section{Objective}

To measure the effect of endonasal dacryocystorhinostomy (DCR) on the health status of patients, using the Glasgow benefit inventory, a validated outcomes measure.

\section{Method}

A postal questionnaire was sent to patients who had undergone endonasal DCR at either the Ninewells Hospital, Dundee, or the Raigmore Hospital, Inverness; telephone follow up was also undertaken. The same surgical technique was used in both centres. All adult patients who were a minimum of 12 months post-operative were included.

\section{Results}

Ninety-two of the 123 patients (75 per cent) contacted completed the questionnaire. The overall mean Glasgow benefit inventory score was +32.7 . Patients' Glasgow benefit inventory scores were also assessed according to their surgical indication, with results as follows: obstruction of lacrimal system, +31.9 ; mucocele, +40.1 ; and dacryocystitis, +19.4. There were 16 revision cases; the Glasgow benefit inventory score for these patients was +49.5 .

\section{Conclusions}

Endonasal DCR scored highly on the Glasgow benefit inventory when compared with other rhinological procedures, including rhinoplasty $(+20)$, endoscopic sinus surgery $(+23)$ and septal surgery (mean ranges from +6 to +24). Endonasal DCR is a successful intervention with demonstrable health benefits for the patient, especially for revision cases. 


\section{Hypocalcaemia following total thyroidectomy for thyroid cancer: 2003-2007 audit}

A Y Isa, O J Hilmi, G W McGarry, K Mackenzie

From the Glasgow Royal Infirmary, Scotland, UK.

\section{Objectives}

To review all thyroid cancer procedures undertaken between 2003 and 2007 in the North Glasgow Trust, with the aim of determining early post-operative hypocalcaemia rates in those undergoing total or completion thyroidectomy, and also of determining the rate of pathology reporting regarding the presence or absence of parathyroids in the thyroidectomy specimen.

\section{Method}

Retrospective audit of thyroid cancer procedures performed between January 2003 and December 2007.

\section{Results}

Eighty-one patients were audited. The prevalence of early hypocalcaemia (i.e. adjusted calcium $<2.0 \mathrm{mmol} / \mathrm{l}$ within 72 hours) was 55 per cent in 2003 but had decreased to 10 per cent in 2007 . The parathyroid reporting rate was 95 per cent in 2007. The preservation of parathyroids decreases the likelihood of early hypocalcaemia but does not guarantee normocalcaemia (the early hypocalcaemia prevalence was 9 per cent in those with preserved parathyroids and 25 per cent in those with inadvertent parathyroidectomy).

\section{Conclusion}

We propose that the search for parathyroids in thyroidectomy specimens should be mandatory. Audit of such pathology reporting increases awareness of inadvertent parathyroidectomy and encourages surgeons to improve their game'.

\section{The frontal osteoplastic flap: an old friend revisited}

A Y Isa, J C Mennie, G W McGarry

From the Glasgow Royal Infirmary, Scotland, UK.

\section{Introduction}

The frontal osteoplastic flap operation was first described in 1894. Since the advent of endoscopic sinus surgery, the applications and use of this procedure have declined The senior author's recent experience suggests a continuing role for the frontal osteoplastic flap in modern rhinology.

\section{Method}

We undertook a retrospective review of patients undergoing a frontal osteoplastic flap procedure, within a tertiary referral centre, under the care of one surgeon. We also reviewed the indications, surgical technique, outcomes and role of novel technical modifications.

\section{Results}

Eight patients underwent a frontal osteoplastic flap procedure between January 2004 and January 2008, for the treatment of mucocele, osteomyelitis, osteoma or recurrent transitional cell papilloma. There were four minor complications (i.e. superficial discharging wound, haematoma and recurrent chronic rhinosinusitis $(n=2))$.

\section{Conclusion}

The frontal osteoplastic flap still has a place in modern rhinology. It should be used when the following situations arise in the frontal sinus: laterally placed lesions; extensive tumours and bony lesions; and in the presence of exposed posterior wall dura.

\section{Manifestations of tuberculosis in the head and neck}

K A McAllister, F B Mac Gregor

From the Gartnavel General Hospital, Glasgow, Scotland, UK.

\section{Objective}

To explore the methods used for diagnosis of tuberculosis presenting in the head and neck, in patients within the Greater Glasgow and Clyde region.

\section{Method}

We included all notified cases of Mycobacterium tuberculosis over a seven-year study period (February 2000 to October 2007).

\section{Results}

Overall, 149 cases (11 per cent of all tuberculosis presentations) had a head and neck presentation. This was most commonly cervical lymphadenopathy (96 per cent), followed by parotid ( 2 per cent), tonsillar ( 1 per cent) and laryngeal (1 per cent) presentations. Excluding laryngeal tuberculosis, the main investigation used in the head and neck region was fine needle aspiration (FNA) (112 patients), followed by excision biopsy ( 57 patients) and core biopsy (19 patients). Fine needle aspiration was diagnostic of tuberculosis in 59 per cent of cases, core biopsy in 94 per cent and excision biopsy in 93 per cent.

\section{Conclusions}

Our findings suggest that core biopsy could be used in preference to both FNA and excision biopsy in the diagnosis of head and neck tuberculosis. Core biopsy has equivalent diagnostic accuracy to excision biopsy and can be performed in the radiology department, therefore reducing operating theatre time.

\section{Ultrasound versus fine needle aspiration in diagnosis of parotid tumours}

L Melia, K MacKenzie, B Irvine, G W McGarry, O J Hilmi

From the North Glasgow Hospital, Scotland, UK.

Objective

To determine the value of ultrasound alone in the diagnosis of parotid tumours, versus ultrasound plus fine needle aspiration and cytology.

\section{Method}

Retrospective study over a two-and-a-half year period, using a neck lump database in north Glasgow.

\section{Results}

From October 2006 to February 2008, 64 patients were clinically diagnosed with parotid tumour. All underwent ultrasonography. Eleven patients were excluded on the basis that ultrasonography excluded a parotid tumour. Thirty-six patients underwent fine needle aspiration (FNA), one underwent core biopsy and one refused further investigation. 12 patients proceeded directly to parotidectomy without having a fine needle aspiration. 25 patients in total underwent parotidectomy. Thirteen patients underwent ultrasonography and FNA. Eight patients had an FNA diagnosis of Warthin's tumour; one diagnosis changed following excision. Five patients had an FNA diagnosis of pleomorphic adenoma; all five diagnoses correlated with the final pathology. Twelve patients 
had an ultrasound diagnosis of pleomorphic adenoma, and proceeded directly to parotidectomy. 10 patients had a final diagnosis of pleomorphic adenoma following surgery, while the remaining 2 had a final diagnosis of Warthin's tumour.

\section{Discussion}

Fine needle aspiration cytology has become the 'gold standard' investigation in the diagnosis of parotid gland tumours. However, the sensitivity and specificity of this investigation depends on the skill of the operator. In our cohort, we established that ultrasound alone enabled a reliable diagnosis of benign parotid tumours; however, when combined with FNA cytology, it had a higher sensitivity.

\section{Exploratory tympanotomy: operative findings in $\mathbf{3 4 0}$ patients}

G Robertson, R Mills

From the Royal Infirmary of Edinburgh, Scotland, UK.

\section{Objective}

To investigate the relative operative diagnosis made in patients undergoing tympanotomy for conductive hearing loss with an intact tympanic membrane.

\section{Method}

We analysed 340 tympanotomies conducted by the senior author at university hospitals in Dundee and Edinburgh.

\section{Results}

The most common diagnosis was ossicular fixation $(n=$ 192,56 per cent) and the most common cause of ossicular fixation was otosclerosis $(n=164,48$ per cent). Ossicular discontinuity was the second most common diagnosis ( $n=103,30$ per cent). Cholesteatoma was found behind an intact tympanic membrane in 2 per cent of cases $(n=7)$.

\section{Conclusion}

Otosclerosis is the most common diagnosis in patients undergoing exploratory tympanotomy for conductive hearing loss.

\section{Side of bleeding in primary and secondary post-tonsillectomy haemorrhage: the Grampian experience}

M Shakeel, G Thiel, C Beattie, J Newton, K W Ah-See

From the Aberdeen Royal Infirmary, Aberdeen, Scotland, UK

\section{Introduction}

The left tonsillar fossa has been observed to be more commonly involved in secondary post-tonsillectomy haemorrhage.

\section{Objectives}

To investigate the side of bleeding in cases of posttonsillectomy haemorrhage, in order to establish the overall post-tonsillectomy bleeding rate and to identify any factors associated with such bleeding.

\section{Patients and method}

We conducted a retrospective audit of 1411 consecutive tonsillectomies with or without adenoidectomy performed over a four-year period (2002-2005). Hospital case notes were reviewed. Along with other parameters, postoperative complications and side of bleeding were recorded.
Results

Of the 1411 procedures, 1111 were tonsillectomies and 300 adenotonsillectomies. The commonest indication was recurrent tonsillitis. Most tonsillectomies were performed using a 'hot' technique (1181/1411, 84 per cent), while 12.6 per cent (178/1411) were conducted using a 'cold' method. Only one adult, male patient was required to return to theatre for control of primary haemorrhage. One hundred and twenty-seven ( 9 per cent) patients were admitted to hospital with secondary bleeding. Of these, 90 per cent (114/127) had undergone hot tonsillectomy; 48 had been operated upon by specialist registrars, 32 by staff grade surgeons and 15 by the consultant. The vast majority of patients were operated upon by right-handed surgeons. Bleeding or a clot was found in the left tonsillar fossa in 45 cases ( 40 per cent), in the right fossa in 16 per cent, and in both fossae in 8 per cent; in 17 per cent of such patients, no evidence of bleeding was found.

\section{Conclusion}

The left tonsillar fossa is more commonly involved in secondary post-tonsillectomy bleeding than the right. Could this be related to the technique of right-handed surgeons?

\section{Is computed tomography scanning of paranasal sinuses} overused in the diagnosis of chronic rhinosinusitis?

\section{G Thiel, D Leiper*, O John†, K W Ah-See*}

From the Ninewells Hospital, Dundee, the *Aberdeen Royal Infirmary, Scotland, and the †Derriford Hospital, Plymouth, England, UK.

\section{Objective}

To assess the use of computed tomography (CT) scanning in the diagnosis of patients with chronic rhinosinusitis.

\section{Method}

We undertook a retrospective review of the clinical notes, radiology reports and CT scans of all ENT patients undergoing CT scanning of the paranasal sinuses in the first three months of 2007 within a university teaching hospital (Aberdeen Royal Infirmary).

Results

One hundred and twenty-three patients with benign disease underwent CT scanning of the paranasal sinuses in the study period. Fifty-one (56 per cent) patients had undergone documented medical treatment before CT, 39 (59 per cent) had undergone documented medical treatment pre-operatively and 66 (54 per cent) had proceeded to surgery. Patients with more severe disease seen on CT scanning were more likely to proceed to functional endoscopic sinus surgery.

\section{Conclusion}

At present, CT scanning is overused in the diagnosis of chronic rhinosinusitis at the Aberdeen Royal Infirmary. Stronger adherence to recommended practice is encouraged, particularly regarding medical treatment before interventions (radiological or surgical).

\section{Post-laryngectomy hypothyroidism and quality of life}

D M Wynne, A Mathie, H Grey, K MacKenzie

From the Glasgow Royal Infirmary, Scotland, UK.

\section{Objective}

To assess the impact of thyroid dysfunction on patientreported quality of life, within a laryngectomy population. 


\section{Method}

Fifty-four patients participated in the study. Each completed a University of Washington quality of life questionnaire and underwent thyroid function testing. Thyroid function was optimised. This assessment was repeated after approximately four months.

\section{Results}

Thirty-nine complete data sets were analysed. Prior optomization of thyroid function, the incidence of hypothyroidism was 11 per cent, that of subclinical hypothyroidism was 63 per cent and that of euthyroidism was 26 per cent. Postintervention, the incidence of hypothyroidism was 0 per cent, that of subclinical hypothyroidism was 36 per cent and that of euthyroidism was 64 per cent. Patients' average University of Washington quality of life scores were 832 pre-intervention and 871 post-intervention $(p=$ 0.2779 ). There appeared to be a correlation between quality of life score and thyroid-stimulating hormone level $\left(\mathrm{R}^{2}=0.9864\right)$.

\section{Discussion}

Despite the fact that a large number of patients had improved thyroid biochemical status post-laryngectomy, we could not detect any significant improvement in composite quality of life scores. It may be that longer term follow up is required. However, it may also be the case that the deleterious effect of laryngectomy outweighs any benefit from improved thyroid function. 